\title{
PENGEMBANGAN ABSENSI SISWA BERBASIS APLIKASI WEB DI SEKOLAH MENENGAH KEJURUAN
}

\author{
Muchlis Harly Winata ${ }^{1)}$, Febiyanti' ${ }^{1)}$, Nuliyani ${ }^{1)}$, Alfiah Fajriani ${ }^{1 *}$ \\ ${ }^{1}$ Universitas Muhammadiyah Kendari, Sulawesi Tenggara, Indonesia \\ Email: alfiah.fajriani@umkendari.ac.id
}

\begin{abstract}
Abstrak
Absensi dapat dikatakan suatu tanda kehadiran yang merupakan bagian dari aktifitas pelaporan yang ada dalam sebuah institusi. Tidak terkecuali pada sistem absensi sekolah untuk menandaai kehadiran siswa umumnya masih dilakukan secara manual, dimana hal ini sangat tidak efisien karena informasi tentang kehadiran bisa saja terjadi kecurangan baik dari pihak murid ataupun guru yang salah dalam menandai kehadiran siswa. Oleh sebab itu sangat perlu untuk diterapkan sebuah teknologi yang dapat membantu proses absensi di sekolah. Sehingga dapat meningkatkan kualitas sistem pada layanan kehadiran siswa. Dalam penelitian ini akan dirancang sebuah sistem absensi yang dapat dilakukan menggunakan smartphone atau pun laptop yang di akses melalui browser. Metode penelitian yang digunakan adalah waterfall, metode ini khusus di gunakan untuk merancang sebuah perangkat lunak atau sebuah software. Software ini menggunakan bahasa pemrograman JavaScript dengan bantuan framework React dan Google Sheet sebagai database. Penelitian ini dilakukan untuk mengatasi masalah absen manual dengan menggantikannya dengan absensi berbasi web aplikasi ini. Dengan adanya sistem ini dapat memberikan solusi agar memudahkan guru dalam mengelola presensi siswa, sehingga mampu meningkatkan kehadiran siswa serta dapat menghitung rekapitulasi absen secara akurat.
\end{abstract}

Kata kunci: absen; google sheet; kehadiran; react ; waterfall.

\section{DEVELOPMENT OF STUDENT ATTENTION BASED ON WEB APPLICATION AT VOCATIONAL HIGH SCHOOLS}

\begin{abstract}
Attendance can be said to be a sign of attendance which is part of the existing reporting in an institution. Absence from the school attendance system for student attendance is usually done manually, which is very inefficient because information about attendance alone will never happen either from the wrong party or the teacher in the student's attendance. Therefore, it is very necessary to apply a technology that can help the attendance process at school. So that it can improve the quality of the system in student attendance services. In this study, an attendance system will be designed that can be done using a smartphone or laptop that can be accessed via a browser. The research method used is Waterfall, this method is specifically used to design a software or a software. This software uses the JavaScript programming language with the help of the React framework and Google Sheets as a database. This research was conducted to overcome the problem of manual attendance by replacing it with this web application-based attendance. With this system, it can provide solutions to make it easier for teachers to manage student attendance, so as to increase student attendance and be able to calculate absentee recapitulation accurately.
\end{abstract}

Keywords: absence; google sheet; presence; react; waterfall.

\begin{tabular}{|cccc|}
\hline Submitted: & Reviewed: & Accepted: & Published: \\
1 September 2021 & 26 September 2021 & 28 September 2021 & 30 September 2021 \\
\hline
\end{tabular}




\section{DECODE: Jurnal Pendidikan Teknologi Informasi, I (2) (2020): $69-75$}

Muchlis Harly Winata, Febiyanti, Nuliyani, Affiah Fajriani

\section{PENDAHULUAN}

Teknologi informasi berperan penting dalam memperbaiki kualitas suatu instansi, penggunaannya tidak hanya sebagai proses otomatisasi terhadap akses informasi, tetapi juga menciptakan akurasi, kecepatan dan kelengkapan sebuah sistem yang terintegrasi, sehingga proses organisasi yang terjadi akan relevan, efektif, terukur, dan fleksibel. Dalam perkembangan teknologi informasi sering dimanfaatkan oleh beberapa instansi, begitu pula SMK Negeri 4 Kendari yang ingin memanfaatkan teknologi informasi sebagai penunjang proses belajar mengajar, salah satu proses penting yang dibutuhkan dalam menunjang kegiatan belajar mengajar adalah absensi kehadiran siswa. Sistem absensi memiliki peranan penting dalam kehidupan sehari-hari terutama di lingkungan sekolah, universitas, pabrik, perkantoran, rumah sakit dan tempat lainnya yang menggunakan absensi sebagai tanda kehadiran. Berbagai jenis sistem kehadiran digunakan dalam berbagai keadaan seperti sekolah dan perusahaan, yaitu sistem berbasis web yang dapat digunakan sebagai pengganti yang tidak hadir (Putri \& Supriyono, 2019).

Sejalan dengan berkembangnya teknologi, sistem absensi dalam dunia pendidikan umumnya masih dilakukan secara manual, tidak terkecuali pada absensi di sekolah SMK Negeri 4 Kendari, dimana hal ini sangat tidak efisien karena informasi tentang teknologi pertama kali diajarkan di dalam dunia pendidikan. Oleh sebab itu sangat perlu untuk diterapkan sebuah teknologi yang dapat membantu proses absensi di sekolah, sehingga dapat meningkatkan kualitas sistem pada layanan kehadiran siswa. Menurut (Husain, Prastian, \& Ramadhan, 2017) absensi adalah ketidahadiran atau kehadiran seseorang yang terlibat dalam suatu organisasi yang mengharuskan adanya pemberitahuan tentang keberadaan dirinya dalam organisasi tersebut. Dalam jurnal yang berjudul Sistem Absensi dan Pelaporan Berbasis Fingerprint dan SMS Gateway dengan menggunakan metode waterfall dengan perancangan sistem absensi dibagi menjadi dua environment, pertama absensi berbasis Fingerprint dapat memberikan kemudahan bagi pihak sekolah untuk data kehadiran siswa. Sedangkan yang kedua dengan menggunakan SMS gateway sebagai media informasi, yang dapat memberikan laporan dari pihak sekolah kepada orang tua siswa atas kehadiran dan tidak kehadiran siswa (Darmawan, Yuliawati, Marcella, \& Firmandala, 2016). Dengan perancangan sistem absensi ini diharapkan dapat membantu pihak sekolah dan orang tua dalam anak mereka.

Menurut jurnal penelitian yang berjudul Analisa dan Perancangan Sistem Absensi Siswa Berbasis Web dan SMS Gateway dengan menggunakan metode prototipe bertujuan memberikan kontribusi dalam dunia pendidikan berupa mengelola absensi siswa secara elektronik, dalam upaya peningkatan efisiensi dan efektivitas pengolahan data serta meminimalkan terjadi kesalahan yang dilakukan oleh pengguna sistem (Santoso \& Yulianto, 2017). Dalam jurnal penelitian berjudul Pembuatan Aplikasi Presensi Perkuliahan Berbasis Fingerprint mengenai tentang sistem absensi berbasis fingerprint guna menunjang proses belajar mengajar, serta menanggulangi kecurangan presensi di kelas. Teknologi ini memang sedang marak dan sangat mendukung karena penerapannya tidak terlalu sulit lagipula terjangkau. Tetapi JSI belum memaksimalkan penerapan presensi fingerprint tersebut karena belum memiliki aplikasi yang mengelola presensi tersebut (Muhammad, Samopa, \& Wibowo, 2013).

Absensi dapat dikatakan suatu pendataan kehadiran yang merupakan bagian dari aktivitas pelaporan yang ada dalam sebuah institusi. Absensi disusun dan diatur sehingga mudah untuk dicari dan dipergunakan ketika diperlukan oleh pihak yang berkepentingan (Setiawan \& Kurniawan, 2015). Contoh-contoh absensi: absen QRCode, absen Fingerprint dan absen RFID.

Absen online adalah sebuah sistem pencatatan kehadiran melalui aplikasi atau platform tertentu yang bisa diakses secara online yang terhubung langsung dengan database secara real time. Absensi diidentifikasi dengan pemanfaatan kehadiran yang dikendalikan oleh masing-masing organisasi atau perusahaan (Lengkong, Fiden, \& Masrikat, 2016). Absensi online dapat memperbaharui metode absensi yang sedang berjalan di Sekolah (Hendrawan, Aprilio, \& Wesley, 


\section{DECODE: Jurnal Pendidikan Teknologi Informasi, I (2) (2021): 69-75}

Pengembangan Absensi Siswa Berbasis Aplikasi Web di Sekolah Menengah Kejuruan

2020). Sebelum memulai atau sesudah mengikuti kegiatan pembelajaran, setiap siswa/i diminta untuk mengisi daftar kehadiran atau presensi sebagai bukti bahwa siswa/i telah hadir dan mengikuti kelas. Selain itu, data absensi sangat diperlukan pihak administrasi sekolah untuk memonitor atau memantau keaktifan siswa/i dalam mengikuti setiap kegiatan dan aktifitas pendukung akademik.

Saat ini SMK Negeri 4 Kendari dalam melakukan pencatatan dan pengelolaan absensi masih secara manual, dimana pencatatan absensi siswa dalam bentuk kertas yang dilakukan oleh guru mata pelajaran. Oleh karena itu, dibutuhkan sebuah aplikasi yang dapat mempermudah kegiatan absensi dalam kegiatan belajar pada SMK Negeri 4 Kendari. Dalam penelitian ini, penulis akan merancang sebuah sistem absensi yang dapat dilakukan menggunakan smartphone ataupun laptop yang di akses melalui browser. Dimana dalam prosesnya, siswa membuka aplikasi browser kemudian mengakses alamat dari aplikasi tersebut dan masukkan Nama, NIS (Nomor Induk Siswa), dan Absen. Setiap siswa hanya membutuhkan sebuah smartphone atau laptop yang terkoneksi dengan jaringan lokal ataupun jaringan internet untuk melakukan absen. Adapun data absensi yang dilakukan siswa dapat dilihat oleh guru dalam bentuk file excel dengan keterangan nama, nis, kehadiran dan tanggal absensi. Berdasarkan solusi tersebut diharapkan proses absensi dapat berjalan maksimal.

\section{METODE}

Dalam merancang sistem agar mendapatkan hasil yang diharapkan, dilakukan tahapantahapan. Secara konseptual siklus pengembangan sebuah sistem terdiri dari; 1) Analisis Sistem, 2) Perancangan Sistem, 3) Pembangunan dan Testing Sistem, 4) Implementasi Sistem, 5) Operasi dan Perawatan, dan 6) Evaluasi Sistem. Siklus tersebut berlangsung secara berulang-ulang. Siklus ini merupakan model klasik SDLC (Systems Development Life Cycle) dari pengembangan sistem informasi. SDLC merupakan langkah-langkah kegiatan agar tercapainya sebuah sistem yang baik sesuai kebutuhan (Dwanoko, 2016). Dalam studi kasus ini, peneliti menggunakan model waterfall. Waterfall merupakan metode pengembangan yang sistematis juga berurutan yang dimulai dari kebutuhan pengguna, perencanaan, pemodelan, konstruksi dan perawatan sistem (Bassil, 2012) Adapun tahapan-tahapan tersebut dapat dilihat pada Gambar 1 berikut ini:

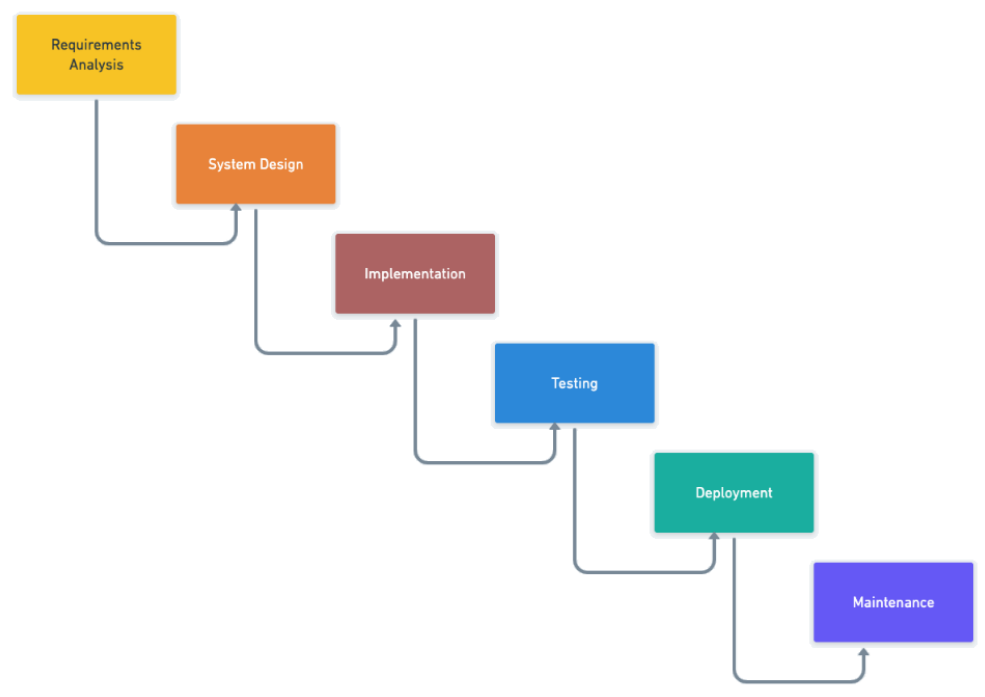

Gambar 1. Model Waterfall

Tahapan pertama adalah requirements analysis, yaitu analisa kebutuhan yaitu hal-hal yang diperlukan untuk perancangan system. Perangkat lunak yaitu Visual Studio Code sebagai sourcecode editor, React sebagai framework javascript modern dan Google Sheet sebagai database. 


\section{DECODE: Jurnal Pendidikan Teknologi Informasi, I (2) (2020): $69-75$}

Muchlis Harly Winata, Febiyanti, Nuliyani, Affiah Fajriani

Mengembangkan aplikasi berbasis web dan perangkat keras seperti komputer/laptop yang dibutuhkan untuk membangun aplikasi. Spesifikasi yang di gunakan untuk development adalah : Macbook Air M1 2020, dan untuk data yang diperlukan adalah Nama, NIS, jam masuk dan jam pulang dari sekolah. Entity data, diperoleh dari Guru di SMK Negeri 4 Kendari.

Tahapan kedua adalah design system, dimana pada tahap ini dirancang sebuah desain dari perancangan aplikasi absensi menggunakan web. Bagaimana desain yang akan digunakan pada UI (User Interface) web setelah dilakukan perancangan desain aplikasi selanjutnya melakukan implementasi terhadap desain UI dari aplikasi berbasis web yang telah dirancang kedalam bahasa pemrograman Javascript. Tahapan ketiga adalah implementation, dimana pada proses ini perancangan aplikasi absensi berbasis web dituangkan kedalam bahasa pemrograman Javascript dan mulai mengembangkan aplikasi menggunakan framework React dan Google Sheet sebagai database, untuk menghasilkan sebuah aplikasi sesuai dengan perancangan. Seluruh fungsi dan desain UI yang terdapat pada perancangan akan disesuikan dengan aplikasi yang akan di hasilkan.

Tahapan keempat adalah testing, dimana pada tahap ini dilakukan pengujian aplikasi atau biasa di sebut testing menggunakan Automation Testing secara menyeluruh, meliputi pengujian fungsional dan pengujian ketahanan aplikasi. Pengujian fungsional dilakukan untuk mengetahui bahwa aplikasi absensi telah berjalan sesuai dengan perancangan. Pengujian ketahanan aplikasi merupakan kemampuan aplikasi untuk berjalan dengan baik pada spesifikasi minimum komputer.

Tahapan kelima adalah deployment, dimana pada tahap ini aplikasi akan di muat ke production server dan siap digunakan oleh guru dan siswa di SMK Negeri 4 Kendari. Tahapan keenam adalah maintanance, dimana pada tahap ini proses perawatan atau maintenance akan dilakukan secara berkala untuk menjaga aplikasi tetap hidup setiap saat. Jika ada bug di production server, maka developer akan segera memperbaiki bug tersebut.

\section{HASIL DAN PEMBAHASAN}

Pengujian alat dan aplikasi absensi pada perangkat laptop dan smartphone dilakukan pada perangkat Samsung M20 dengan Wi-Fi $802.11 \mathrm{~b} / \mathrm{g} / \mathrm{n}$. Pengujian akses ke aplikasi dilakukan pada perangkat tersebut, aplikasi berhasil jalan dan sukses mengirim data.

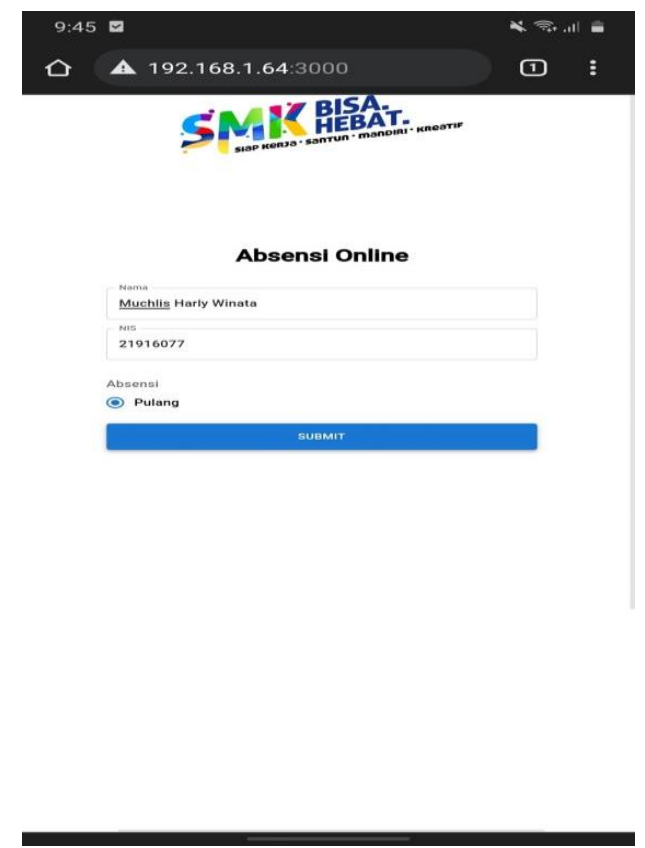

Gambar 2. Pengujian di Samsung M20 


\section{DECODE: Jurnal Pendidikan Teknologi Informasi, I (2) (2021): $69-75$}

Pengembangan Absensi Siswa Berbasis Aplikasi Web di Sekalah Menengah Kejuruan

Pengujian dilakukan pada perangkat ini, aplikasi berhasil di jalankan dibuktikan dengan gambar di bawah ini yang sudah masuk ke menu utama

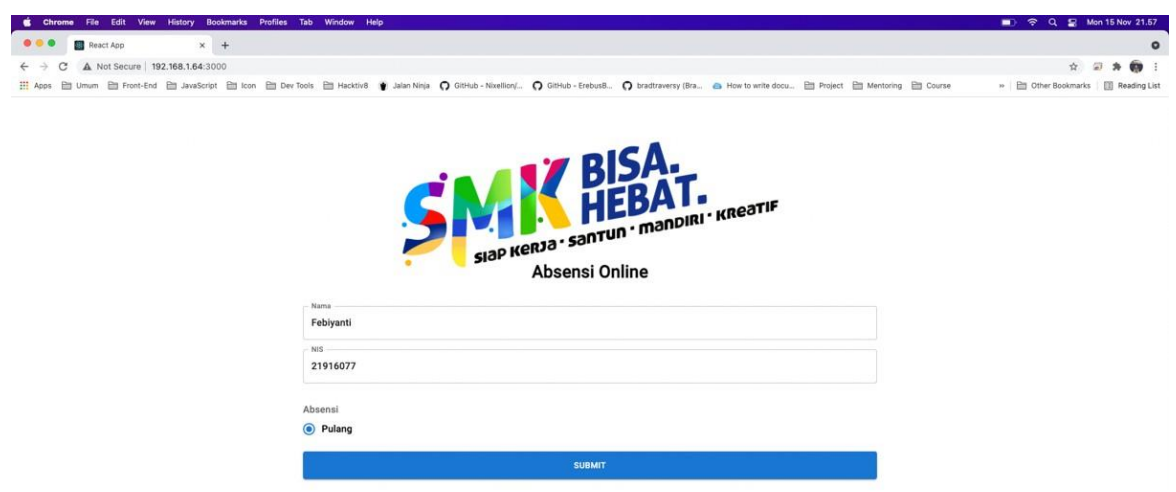

Gambar 3. Pengujian di Macbook Air

SMK Negeri 4 Kendari merupakan salah satu Sekolah Menengah Kejuruan yang sering di juluki Sekolah IT yang berlokasi di Sulawesi Tenggara. Dalam kesehariannya sepertimerekap data hadir siswa menggunakan secara manual sehingga kurang efektif untuk merekap data. Penelitian pengembangan ini berhasil di lakukan dan menghasilkan absensi siswa menggunakan React dan Google Sheet. Pengujian di atas dilakukan secara realtime menggunakan framework dan database di atas, berikut di bawah ini tampilan aplikasi dan datayang ada di Google Sheet.

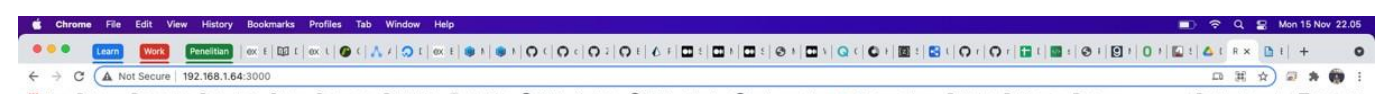
$\leftarrow \rightarrow C$ (A Not Secure 192.168.1.64:3000

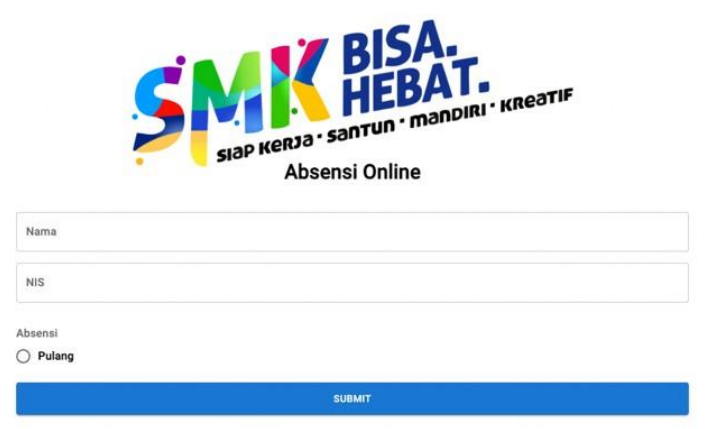

Gambar 4. Tampilan Dashboard Absen

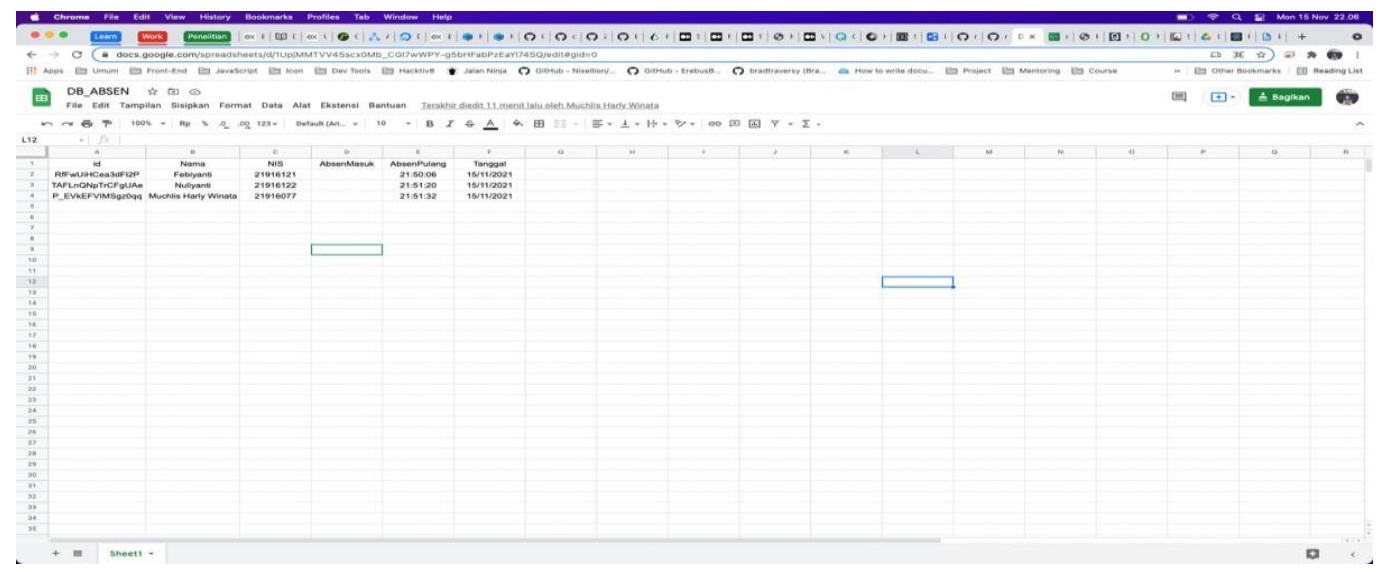

Gambar 5. Tampilan Google Sheet sebagai Database 


\section{DECDDE: Jurnal Pendidikan Teknologi Informasi, I (2) (2020): $69-75$}

Muchlis Harly Winata, Febiyanti, Nuliyani, Alfiah Fajriani

\section{KESIMPULAN DAN SARAN}

Berdasarkan hasil penelitian dapat diambil kesimpulan yaitu: (1) sistem absensi yang dirancang untuk mencatat kehadiran siswa dapat berjalan dengan baik pada Laptop ataupun Smartphone, dan (2) sistem ini dapat di akses secara online maupun offline, dan menggunakan stack techonolgy yaitu React dan Google Sheet sebagai database serta Google Data Studio dapat digunakan sebagai tools untuk reporting absen karna terintegrasi dengan Google Sheet.

Adapun saran yang dapat diberikan yaitu: (1) sistem absensi ini masih terbatas dalam pemilihan keterangan yaitu hadir dan tidak hadir. Kedepannya dapat ditambahkan keterangan lain seperti, sakit dan izin, dan (2) sistem ini belum memiliki pemilahan data otomatis untuk kelas yang berbeda. Kedepannya absen dapat dipilah berdasarkan kelas dan mata pelajaran.

\section{DAFTAR PUSTAKA}

Bassil, Y. (2012). A Simulation Model For The Waterfall Software Development Life Cycle. arXiv preprint arXiv:1205.6904. International Journal of Engineering \& Technology (iJET), 2(5), 1-7.

Darmawan, A., Yuliawati, D., Marcella, O., \& Firmandala, R. (2016). Sistem Absensi dan Pelaporan Berbasis Fingerprint dan SMS Gateway. Explore: Jurnal Sistem informasi dan telematika (Telekomunikasi, Multimedia dan Informatika), 7(2), 33-42.

Dwanoko, Y. S. (2016). Implementasi Software Development Life Cycle (SDLC) Dalam Penerapan Pembangunan Aplikasi Perangkat Lunak. Jurnal Teknologi Informasi: Teori, Konsep, dan Implementasi, 7(2), 83-94.

Hendrawan, A. Y., Aprilio, B., \& Wesley, R. A. (2020). Perancangan Aplikasi Absensi Smp Terang Bagi Bangsa. Electro Luceat, 6(2), 274-281. https://doi.org/10.32531/jelekn.v6i2.264

Husain, A., Prastian, A. H. A., \& Ramadhan, A. (2017). Perancangan Sistem Absensi Online Menggunakan Android Guna Mempercepat Proses Kehadiran Karyawan Pada PT. Sintech Berkah Abadi. Technomedia Journal,2(1 Agustus), 105-116. https://doi.org/10.33050/tmj.v2i1.319

Lengkong, O. H., Fiden, D. H., \& Masrikat, A. (2016). Sistem Informasi Absensi Real-Time di Universitas Klabat. CogITo Smart Journal, 2(2), 216-228. http://dx.doi.org/10.31154/cogito.v2i2.31.216-228

Muhammad, N. A., Samopa, F., \& Wibowo, R. P. (2013). Pembuatan Aplikasi Presensi Perkuliahan Berbasis Fingerprint (Studi Kasus: Jurusan Sistem Informasi Institut Teknologi Sepuluh Nopember Surabaya). Jurnal Teknik ITS, 2(3), A465-A469.

Pressman, R. S. (2012). Rekayasa Perangkat Lunak (Pendekatan Praktisi) Edisi 7 Buku 1. Yogyakarta: Andi CV.

Putri, D. P. M., \& Supriyono, H. (2019). Rancang Bangun Sistem Presensi Berbasis QR Code Menggunakan Framework Codeigniter (Studi Kasus Kehadiran Asisten Praktikum). Jurnal insypro, 4(1), 1-9.

Santoso, H., \& Yulianto, A. W. (2017). Analisa dan Perancangan Sistem Absensi Siswa Berbasis Web dan SMS Gateway. MATRIK: Jurnal Manajemen, Teknik Informatika Dan Rekayasa Komputer, 16(2), 65-75. 
DECDDE: Jurnal Pendidikan Teknologi Informasi, I (2) (2021): 69 -75

Pengembangan Absensi Siswa Berbasis Aplikasi Web di Sekolah Menengah Kejuruan

Setiawan, E. B., \& Kurniawan, B. (2015). Perancangan Sistem Absensi Kehadiran Perkuliahan dengan Menggunakan Radio Frequency Identification (RFId). Jurnal CoreIT: Jurnal Hasil Penelitian Ilmu Komputer dan Teknologi Informasi, 1(2), 44-49.

\section{How to cite:}

Winata, M. H., Febiyanti, F., Nuliyani, N., \& Fajriani, A. (202I). Pengembangan Absensi Online Berbasis Aplikasi Web di Sekolah Menengah Kejuruan. DECDDE: Jurnal Pendidikan Teknalogi Infarmasi, /(2), 69-75. DDI: http://dx.dai.org/10.51454/decade.vii2.26 